\title{
PEQUENO VAREJO SUPERMERCADISTA NA REGIÃO METROPOLITANA DE BELO HORIZONTE
}

\section{SMALL RETAIL SUPERMARKET IN THE METROPOLITAN REGION OF BELO HORIZONTE}

Recebido em 22.06.2017. Aprovado em 13.12.2017 Avaliado pelo sistema double blind review

Hudson Soares Moreira

hudsonsmoreira@gmail.com

Centro Universitário UNIHORIZONTES - Belo Horizonte - MG

Wendel Alex Castro Silva

wendel.silva@unihorizontes.br

Centro Universitário UNIHORIZONTES - Belo Horizonte - MG

Marcia Athayde Moreira

athayde.marcia@gmail.com

Universidade da Amazônia (UNAMA) - Ananindeua - PA

Nayara Kelly Batista

nayarakellybatista09@gmail.com

Centro Universitário UNIHORIZONTES - Belo Horizonte - MG

\section{Resumo}

Este estudo objetivou apontar as características dos gestores e dos estabelecimentos pertencentes ao pequeno varejo supermercadista organizado em redes da região metropolitana de Belo Horizonte. A abordagem teórica ancorou-se em pesquisas referentes a pequenas empresas, varejo supermercadista e empreendedorismo coletivo (redes). Metodologicamente a pesquisa é classificada como descritiva de abordagem quantitativa, mediante a aplicação de um questionário a 60 empreendedores do varejo supermercadista organizado em redes da região metropolitana. Os resultados apontam o porte das lojas e dos supermercados de bairro, com abrangência reduzida e altos faturamentos, chegando alguns a faturar mais de $\mathrm{R} \$ 750$ mil por mês, indicando que a estruturação em redes favoreceu o crescimento. Nas redes estudadas não há loja inaugurada há menos de dois anos, sugerindo que quem está no mercado luta para se manter e fortalecer seu negócio, não se arriscando a inaugurar novas lojas. Neste cenário, $63 \%$ das lojas estão estabelecidas há mais de 10 anos, indicando o fortalecimento da confiança entre os proprietários e a clientela. Quando comparados com os dados de supermercados não organizados em redes fornecidos pela AMIS, infere-se nessa pesquisa que as lojas organizadas em redes conseguiram atingir um nível de desenvolvimento melhor do que as demais lojas não organizadas, concluindo que, para elas, a participação em redes é um aspecto favorável da sua gestão para a sustentabilidade do negócio.

Palavras-chaves: Sustentabilidade financeira. Varejo supermercadista. Redes interorganizacionais.

\section{Abstract}

This study aimed to show the characteristics of the managers and establishments belonging to the small retail supermarket networks of the metropolitan region of Belo Horizonte. The theoretical approach was anchored in researches related to small companies, retail supermarket and collective network entrepreneurship. Methodologically the research is classified as descriptive of quantitative approach, through 
the application of a questionnaire to sixty entrepreneurs of the retail supermarket networks of the metropolitan region. The results showed the size of stores and supermarkets in the neighborhood, with reduced coverage and high billings, some of which reached more than $\mathrm{R} \$ 750,000$ per month, indicating that network structuring favored growth. In the networks studied there is no store inaugurated less than two years ago, evidencing that those who are in the market struggle to maintain and strengthen their business, not risking to inaugurate new stores. In this case, sixty and three percent of stores have been established for more than ten years, indicating the strengthening of trust between owners and customers. When compared to the data of supermarkets not organized in networks provided by AMIS, it is inferred in this research that the stores organized in networks managed to reach a level of development better than the other unorganized stores, concluding that, for them, the participation in Is a favorable aspect of its management for the business sustainability.

Keywords: Financial Sustainability. Retail supermarket. Interorganizational networks.

\section{Introdução}

Este artigo versa sobre a organização do pequeno varejo supermercadista. No Brasil, os pequenos supermercadistas estão em desvantagem quando comparados com os médios e de grande porte. Observase que, quanto a questões legais, de higiene e vigilância sanitária, estão sujeitos às mesmas exigências dos grandes supermercadistas, mas em contrapartida, em relação a elementos de competitividade, como por exemplo, poder de barganha em relação aos fornecedores, acesso a capital de terceiros, qualificação e retenção de mão de obra, os pequenos sofrem com a falta de competitividade. Neste cenário, os pequenos supermercadistas vêm ao longo dos últimos anos lidando com as adversidades, se estruturando e se organizando em redes a fim de manter sua sustentabilidade financeira (KLEIN; PEREIRA, 2016).

Mesmo diante das dificuldades em questão, dados da Associação Brasileira de Supermercados - ABRAS, revelam que no Brasil o setor está em crescimento constante, tanto que em abril de 2012 o número de lojas alcançou 82 mil unidades, empregando 967,7 mil pessoas e possuindo 206,6 mil checkouts. Assim, conhecer o setor, seus produtos, processos e inovações, a fim de diminuir as possibilidades de erro na escolha de suas ações, deve permitir ao empreendedor alcançar as metas e os objetivos traçados, aumentando as chances de o negócio ser bem sucedido, gerando lucro para os sócios e garantindo o retorno do capital investido.

Assim, partindo do pressuposto de que os pequenos supermercadistas estão se estruturando e se organizando para garantir sua sustentabilidade financeira, este estudo objetivou descrever como 0 estabelecimentos pertencentes ao pequeno varejo supermercadista da região metropolitana de Belo Horizonte organizado em redes está se estruturando. Justifica-se esta pesquisa pela importância dos proprietários dos estabelecimentos pesquisados conhecerem a si próprios e a realidade do setor de varejo supermercadista da região metropolitana de Belo Horizonte.

Este artigo está estruturado em cinco seções: primeira, aspectos introdutórios, como contextualização, problema de pesquisa, objetivo e justificativa; segunda, referencial teórico; terceira, aspectos metodológicos; quarta, análise empírica; e quinta, considerações finais.

\section{Pequenas empresas, sustentabilidade e empreendedorismo coletivo}

Pequenos negócios podem ser caracterizados por mais de uma forma. De acordo com os critérios da Lei Complementar 123/06 (Estatuto Nacional da Microempresa e da Empresa de Pequeno Porte), em que a definição de microempresa e de empresa de pequeno porte, esta se refere com base no faturamento auferido em cada ano calendário, não devendo ultrapassar $\mathrm{R} \$ 3,6$ milhões/ano (BRASIL, 2006). Já 0 SEBRAE (2012) adota como critério de classificação dos empreendimentos o número de empregados contratados. Para esse fim, estabelece que a pequena empresa não deve ter mais do que 99 empregados para os ramos indústria e construção civil ou 49 empregados para os ramos de comércio e serviços. 
Embora estes sejam os critérios gerais, cada estado brasileiro possui uma variedade de critérios para classificar as micro e pequenas empresas, de acordo com a sua situação econômica e fiscal própria que pode abranger não somente o faturamento, como também a quantidade de empregados e o segmento no qual se enquadram (SEBRAE, 2012).

Por último, ressalta-se a classificação da Lei das Sociedades Anônimas, que estabelece, em seu artigo 195 (Lei 11.638/2007), que sociedades de grande porte são: "[...] a sociedade ou conjunto de sociedades sob controle comum que tiver no exercício social anterior, ativo total superior a $\mathrm{R} \$ 240.000 .000,00$ (duzentos e quarenta milhões de reais) ou receita bruta anual superior a $\mathrm{R} \$ 300.000 .000,00$ (trezentos milhões de reais)" (BRASIL, 2007).

Dessa forma, estabeleceu-se que as empresas que não atingirem os patamares estabelecidos de faturamento ou ativo total anteriormente referido são de médio porte. Logo, as empresas consideradas de médio porte são aquelas cujo faturamento se enquadra entre $\mathrm{R} \$ 3.600 .000,00$ (Lei Complementar 123/06) e $R \$ 300.000 .000,00$ (Lei 11.638/2007).

De acordo com dados divulgados pelo site Diário do Comércio (2017) no primeiro mês de 2017, foram criadas 194.199 empresas no país, sendo considerado o maior número desde 2010. Este crescimento é justificado pelo aumento da recessão econômica e o desemprego fazendo com que as pessoas busquem novas fontes de renda por meio da abertura de novos negócios.

Alves et al. (2013) argumentam que em uma economia baseada no conhecimento, a aprendizagem assume papel importante e exige flexibilidade e ação de empreendedores dispostos a manter ou melhorar posições de mercado. Logo, dois elementos parecem ser cruciais para a sustentabilidade da vantagem competitiva das empresas: estruturas organizacionais mais flexíveis; e inovação contínua, o que permite à empresa criar e entregar maior valor para clientes. "Dentro deste cenário, Pequenas e Médias Empresas (PME) são pressionadas por empresas maiores, que têm melhores recursos para estabelecer estratégias competitivas" (ALVES et al., 2013, p. 62).

Beijerse (2000), que argumenta, a partir de pesquisa realizada com pequenas e médias empresas na Holanda, que essas não possuem praticamente nenhuma política de gestão de conhecimento em nível estratégico, geralmente não possuem metas e não possuem conhecimento em nível tático necessário para tornar a estrutura facilitadora do desenvolvimento da organização (BEIJERSE, 2000), mas possuem muitos instrumentos de gestão na área operacional e na área operacional. Muitas vezes, mesmo sem perceber, desenvolvem e compartilham instrumentos de gestão de conhecimento (BEIJERSE, 2000).

Nesse contexto, ressalta-se 0 alto e incômodo índice de extinção das pequenas empresas, dado que até 0 terceiro ano de atividade $60 \%$ das organizações encerram suas operações (LENZI; KIESEL, 2009). Ferronato (2011) afirma que a maioria dos pequenos empreendimentos não sobrevive aos primeiros cinco anos contados da data de início de suas atividades em um contexto no qual se admite que a sobrevivência dessas empresas é condição indispensável para o desenvolvimento econômico do país.

Assim, considera-se que o pequeno varejo precisa estar estruturado e deve buscar a sustentabilidade do pequeno negócio no empreendedorismo coletivo, viabilizado por meio de redes de cooperação, que buscam estratégias coletivas para enfrentar a concorrência e vêm sendo estudadas como uma alternativa para a competitividade das PMEs. Dentro de redes, essas empresas compartilham informações, melhoram sua capacidade de aprender e têm outros benefícios, como compra conjunta, melhorias de marketing, redução de custos e maior poder de barganha (ALVES et al., 2013; KLEIN; PEREIRA, 2016).

Nesse contexto, destaca-se o trabalho de Ferreira et al. (2008), cujo objetivo foi mostrar que as redes organizacionais são viáveis, representando uma possibilidade e um caminho a ser seguido, tendo como foco de análise pequenas empresas do setor do varejo alimentar (supermercados). Para Ferreira et al. (2008), a constituição de redes de negócios tem representado um diferencial positivo para os pequenos supermercadistas, impactando diretamente suas performances operacional, econômica e financeira. 
Ferreira et al. (2008) realizaram pesquisa exploratória e qualitativa a partir de dados coletados da Associação Brasileira de Supermercados (ABRAS) em 2005, em que identificaram que o pequeno varejo supermercadista organizado em redes cresceu 11,09\% em 2004 em relação a 2003, enquanto o setor supermercadista cresceu apenas $2,57 \%$. Tal crescimento foi atribuído ao profissionalismo do setor, ao reconhecimento do público corporativo e à aproximação com o Poder Público. Os dados levantados indicaram a eficiência das redes, por exemplo, o faturamento médio anual por checkout de $\mathrm{R} \$ 933,7$ mil dos pequenos organizados em rede contra uma média de $\mathrm{R} \$ 1,2$ milhão de faturamento por checkout dos 300 maiores supermercados do País. Ao mesmo tempo, a produtividade também aumentou de uma média de 98 m2 de loja por checkout em 2003, contra 111 m2 de loja por checkout em 2004.

Dados de 2004 apontam que $70 \%$ das redes de pequenos supermercadistas têm menos de cinco anos de atividades, $60 \%$ têm mais de 20 associados e $40 \%$ mais de 30 lojas cada uma. Faturaram em $2004 \mathrm{R} \$ 12,02$ bilhões, participando com $12,3 \%$ do faturamento total do segmento supermercadista. O número de lojas no Brasil totalizou 2.807 com 12.344 checkouts significando uma média de 4,4 checkouts por loja.

Outra etapa da pesquisa realizada evidenciou três importantes pontos: a) os motivos que levam os pequenos supermercados a se associarem a uma rede de negócios; b) os objetivos da associação; e, c) os ganhos obtidos. Entre os motivos, destacam a melhoria no poder de barganha com os fornecedores $(59,5 \%)$, a sobrevivência ante a concorrência $(29,7 \%)$, o acesso a um maior número de fornecedores $(5,4 \%)$ e a operação com um mix mais qualificado e um melhor relacionamento com o cliente (ambos com 2,7\%).

No item "b" os principais objetivos esperados com o ingresso em uma rede foram: compra de produtos mais baratos e fortalecimento da união e da integração dos associados (ambos com 29,7\%), crescimento e sobrevivência no mercado (24,3\%), negociação direta com a indústria $(10,8 \%)$ e conquista de melhores prazos para pagamento $(5,4 \%)$.

Quanto ao item "c", os ganhos obtidos por quem já participa de uma rede foram: melhores condições de negociações com fornecedores (43,2\%), aumento das vendas $(18,9 \%)$, redução de custos $(5,4 \%)$ e aumento da rentabilidade $(2,7 \%)$.

Em suma, os itens "a", "b" e "c" são vistos como vantagens para o ingresso em uma rede, de outro lado, as dificuldades encontradas na participação em redes, como questões culturais $(70,3 \%)$, burocracias legais $(64,9 \%)$, falta de cooperação e comprometimento entre os associados $(62,2 \%)$, dificuldade de relacionamento com os grandes fornecedores $(59,5 \%)$ e dificuldade para unificação e padronização do mix $(48,6 \%)$ são destacadas como desvantagens de ser associado.

A pesquisa revelou também como pontos positivos a uniformidade no treinamento operacional e gerencial, nos processos de recrutamento e seleção e na utilização de marcas próprias.

Ferreira et al. (2008) concluíram que, devido às dificuldades enfrentadas quando o pequeno varejista opera de forma isolada em sua busca por crescimento e sustentabilidade, o associativismo tem crescido de forma organizada. As redes organizacionais surgem nesse novo contexto, por meio do cooperativismo, para obter novas fontes de vantagens competitivas necessárias no atual cenário marcado, em razão da concorrência acirrada e da alta competição (FERREIRA et al., 2008).

Segundo Gronum, Varreynne e Kastelle (2012) a associação entre redes possui uma relação positiva com o crescimento das vendas, entretanto esta variável não possui relação com rentabilidade e produtividade ao analisar a contribuição da articulação em rede na inovação e desempenho de pequenas e médias empresas.

Ao analisar a maturidade interorganizacional de empresas que atuam em rede, Rolt, Dias e Peña (2017) descrevem que este construto é um determinante importante para a sua continuidade, sendo importante também a adoção de modelos de gestão de governança que viabilizem a integração e cooperação dentre os participantes.

\section{Setor supermercadista}

De acordo com Mendes (2012), o rápido desenvolvimento tecnológico ocorrido nas últimas décadas do 
século XX propiciou o surgimento da maioria dos varejistas nos formatos em que é conhecido hoje. Novas indústrias começaram a produzir mais. Com isso, aumentou a concorrência. $\mathrm{E}$ com as várias mudanças socioeconômicas mais produtos e serviços passaram a disputar a atenção do consumidor.

Las Casas (2000) define o varejo como uma unidade de negócio que compra mercadorias de fabricantes e outros distribuidores e vende diretamente ao consumidor final. Richert1 (1954), citado por Las Casas (2000, p. 17), define varejo como "[...] o processo de compra de produtos em quantidade relativamente grande dos produtores atacadistas e outros fornecedores e posterior venda em quantidade menor ao consumidor final".

Independentemente da forma com que as definições varejistas são apresentadas, trata-se de comercialização a consumidores finais (MESQUITA, 2004). Em relação ao formato do varejo supermercadista, o autor classifica as lojas pela área de vendas em metros quadrados.

Para Mesquita (2004), as mercearias combinadas com açougue, ao implantarem o autosserviço, resultaram em supermercados que adicionaram itens fora do ramo alimentício, acompanhando a tendência de conveniência para compras. Já os hipermercados tiveram crescimento expressivo na primeira década do século XXI, sendo que a característica de um hipermercado é a existência de seções, tais como: mercearia, hortifruti, carnes e aves, padaria, frios e laticínios, bazar, têxtil e eletroeletrônicos.

Segundo Melo (2010), a história das redes de pequenos supermercados inicia-se com a implantação do Plano Real, que favoreceu sua expansão e a implantação de grandes redes supermercadistas mundiais no Brasil.

Essa dinâmica dos últimos 20 anos fez com que os pequenos varejistas supermercadistas se defrontassem com uma nova situação de competitividade e buscassem estratégias e recursos para garantir sua permanência no mercado. Como solução, os pequenos supermercados passaram a associar-se em redes, inicialmente, para formar centrais de compra, com o objetivo de reduzir custos na aquisição de mercadorias e poder diminuir o preço de venda aos consumidores finais (WILDER, 2003).

A seguir, apresenta-se o Quadro 1 que descreve a classificação dos formatos de varejo segundo Las Casas (2000).

\begin{tabular}{|l|l|l|l|l|l|}
\hline $\begin{array}{l}\text { Formato das } \\
\text { lojas }\end{array}$ & $\begin{array}{l}\text { Área de } \\
\text { vendas/m² }\end{array}$ & $\begin{array}{l}\text { Número } \\
\text { médio } \\
\text { de itens }\end{array}$ & $\begin{array}{l}\% \text { de } \\
\text { vendas } \\
\text { não } \\
\text { alimentos }\end{array}$ & $\begin{array}{l}\text { Números } \\
\text { de } \\
\text { checkouts }\end{array}$ & Seções \\
\hline $\begin{array}{l}\text { Loja de } \\
\text { conveniência }\end{array}$ & $50-250$ & 1.000 & 3 & $1-2$ & $\begin{array}{l}\text { Mercearia, bazar, frios e laticínios, } \\
\text { snacks. }\end{array}$ \\
\hline $\begin{array}{l}\text { Supermercado } \\
\text { compacto }\end{array}$ & $300-700$ & 4.000 & 3 & $2-6$ & $\begin{array}{l}\text { Mercearia, bazar, hortifruti, carnes } \\
\text { e aves, frios e laticínios. }\end{array}$ \\
\hline $\begin{array}{l}\text { Supermercado } \\
\text { convencional }\end{array}$ & $700-2500$ & 9.000 & 6 & $7-20$ & $\begin{array}{l}\text { Mercearia, bazar, hortifruti, carnes } \\
\text { e aves, frios e laticínios, peixaria, } \\
\text { padaria. }\end{array}$ \\
\hline Hipermercado & $7000-16000$ & 45.000 & 30 & $55-90$ & $\begin{array}{l}\text { Mercearia, bazar, hortifruti, carnes } \\
\text { e aves, frios e laticínios, peixaria, } \\
\text { padaria, têxtil e eletrônico. }\end{array}$ \\
\hline
\end{tabular}

Quadro 1 - Classificação dos formatos das lojas de varejo

Fonte: Adaptado de Las Casas, 2000.

Barbosa et al. (2008) argumentam que, inicialmente, as redes foram formatadas como uma central de compras, mas ao longo do tempo as redes foram evoluindo, criando centrais de recebimento e distribuição 
de mercadorias, além de procedimentos comuns relacionados às áreas de publicidade e finanças e integração tecnológica, culminando com a contratação de executivos de mercado para gerir a rede de forma neutra.

Segundo Ferreira et al. (2008) as centrais de compras nos últimos anos ganharam força e destaque, passando a ser vistas com mais atenção pelo mercado. São organizações com características próprias, que a cada dia ampliam sua área de atuação na gestão dos negócios de seus associados. Até o fim do século XX, o Brasil possuía 60 centrais de compras de pequenos supermercadistas e, aproximadamente, 150 lojas associadas. Em 2005, o número subiu para 150 centrais, com aproximadamente 3.050 lojas, tendo sido reduzido para 130 redes em 2009, com 3.540 lojas associadas (MELO, 2010). De acordo com estatísticas atualizadas da ABRAS (2012) Minas Gerais tem 11 redes de pequenos supermercados entre as 30 maiores redes do Brasil.

Las Casas (2006) discorre que os supermercados sugiram nos Estados Unidos na década de 1930, enquanto que no Brasil apareceram na década de 1950. Uma pioneira no sistema self serfice, as Lojas Americanas, inaugurada em 1952, no Rio de janeiro. O autor atesta a tendência de os grandes supermercados se transformarem em hipermercados, uma mistura de supermercados com lojas de descontos, que vendem produtos alimentícios, material de limpeza, eletrodomésticos e artigos esportivos, entre muitos outros produtos (LAS CASAS, 2006).

Wilder (2003) argumenta que a abertura do mercado brasileiro, em 1990, e a estabilização econômica, em 1995, favoreceram a expansão das redes de supermercados nacionais e a implantação de grandes redes supermercadistas mundiais no Brasil. Essa nova dinâmica fez com que os pequenos varejistas supermercadistas se defrontassem com uma nova situação de competitividade e buscassem estratégias e recursos para garantir sua permanência no mercado (WILDER, 2003). Os pequenos varejos também aprenderam a se organizar em redes, para ganhar competitividade e garantir a sua sobrevivência (RIBOLDAZZI, 2016).

Segundo Campos et al., (2016), Klein e Pereira (2016), alguns fatores são determinantes para a atuação em rede de empresas. Dentre eles estão a motivação dos empresários a se organizarem em rede e a possibilidade de realizarem compras em conjunto, diminuindo assim os custos, como também, relações de confiança, estabilidade, interdependência, cooperação e benefícios mútuos são fatores que determinam e mantém esta articulação.

A articulação em rede também é uma estratégia utilizada para alavancar competitividade e também agregar mais valor às organizações participantes. Entretanto, é importante ressaltar também as motivações que levam estas empresas a deixarem este modelo de articulação como a falta de confiança, oportunismo, compromisso e individualismo de alguns membros (KLEIN; PEREIRA, 2016).

Dados da Associação Mineira de Supermercados (AMIS, 2017) descrevem que o setor supermercadista no Brasil obteve faturamento de 338,7 bilhões em 2016, com crescimento de 7,1\% em comparação ao ano anterior e, o setor representa cerca de $5,4 \%$ do Produto Interno Bruto (PIB) nacional.

\section{Realidade supermercadista da região metropolitana de belo horizonte}

De acordo com dados coletados na Associação Mineira de Supermercados (AMIS), em 2017 o setor obteve crescimento de $3,74 \%$ no mês de Abril em comparação ao mesmo mês no ano passado, e a previsão é de alavancagem das vendas.

O número total de pontos de vendas (supermercados) em Minas Gerais foi de 6840, dos quais 83 razões sociais cadastradas (uma razão social pode ter várias lojas) são associadas à AMIS, sendo que 33 são classificadas como pequenas empresas, com até 49 empregados, conforme classificação do SEBRAE (2012).

As 33 empresas cadastradas representam o universo dos pequenos varejos supermercadistas, cujas principais características são apresentadas no Quadro 2. 


\begin{tabular}{|c|c|c|c|c|}
\hline Dados do Setor & Mínimo & Média & Mediana & Máximo \\
\hline Número de checkout & 1 & 3,6 & 3 & 7 \\
\hline $\mathrm{M}^{2}$ por loja & $100 \mathrm{~m}^{2}$ & $383 \mathrm{~m}^{2}$ & $355 \mathrm{~m}^{2}$ & $900 \mathrm{~m}^{2}$ \\
\hline Número de empregados & 3 & 18,2 & 14 & 45 \\
\hline Faturamento por Loja & 117.000 & 3.007 .456 & 252.000 & 9.364 .228 \\
\hline Faturamento por checkout & 70.000 & 817.987 & 698.690 & 2.341 .057 \\
\hline Faturamento por funcionário & 27.998 & 158.519 & 161.236 & 295.910 \\
\hline Faturamento por $\mathrm{m}^{2}$ & 700 & 8.346 & 7.256 & 22.667 \\
\hline Funcionários por checkout & 1,5 & 4,9 & 5 & 11 \\
\hline Funcionários por $100 \mathrm{~m}^{2}$ & 1,3 & 4,8 & 4 & 11 \\
\hline Checkout por loja & 1 & 3,4 & 3 & 7 \\
\hline $\mathrm{M}^{2}$ por checkout & $50 \mathrm{~m}^{2}$ & $114 \mathrm{~m}^{2}$ & $110 \mathrm{~m}^{2}$ & $200 \mathrm{~m}^{2}$ \\
\hline
\end{tabular}

Quadro 2 - Características do pequeno varejo supermercadista em Minas Gerais Fonte: AMIS (2012).

O Quadro 2 mostra que o pequeno varejo supermercadista se organiza em lojas que variam de $100 \mathrm{~m}^{2}$ até $900 \mathrm{~m}^{2}$, tendo, em média, 3,6 checkouts por loja e 18,2 empregados por supermercado. Os pequenos varejos faturaram em 2011, em média, pouco mais de três milhões de reais por ano, sendo que a loja que teve 0 menor faturamento faturou 117 mil reais, enquanto que a loja que mais faturou superou o faturamento de nove milhões.

Os números absolutos permitem calcular os índices de produtividade, como o faturamento médio por checkout, de aproximadamente 818 reais mil por ano, enquanto que o faturamento médio por empregado foi de 158,5 mil reais e o faturamento médio por metro quadrado foi de aproximadamente oito mil reais. Observa-se também que os pequenos varejos possuem, na média, um checkout a cada $114 \mathrm{~m}^{2}$ de loja e aproximadamente cinco funcionários por checkout.

A perspectiva para o ano de 2013 foi de geração de 8 mil novos postos de trabalho, chegando a empregar 156 mil pessoas no setor. Cerca de $70 \%$ dos supermercados estabelecidos em Minas Gerais são de pequeno e de médio porte.

Em outra perspectiva têm-se as redes de negócios. Dados fornecidos pela AMIS (2013) relativos ao último levantamento realizado (AMIS, 2010), revelam que são 39 centrais de negócios cadastradas na AMIS no estado de Minas Gerais, tendo 162 supermercados associados. Dessas 39 redes, 7 possuem sede na região metropolitana de Belo Horizonte: Rede Arrastão, Rede Fácil, Rede Gerais, Rede Mania, Rede Super Varejista, Rede Valor e Rede Paranaíba.

\section{Metodologia}

Este estudo é do tipo descritivo, de abordagem quantitativa, utilizando como método a estratégia de survey. Para a coleta de dados desta pesquisa, foi utilizado o questionário estruturado, aplicados mediante entrevista pessoal com esta finalidade. Para tanto, previamente, foi feito contato por telefone com os proprietários dos supermercados, com o intuito de apresentar e explicar a relevância da pesquisa, bem como de ressaltar a importância da participação da empresa no estudo. Após deixar claro os objetivos da pesquisa e o sigilo da identidade da empresa e dos respondentes, foi agendada a data para a aplicação do questionário.

Delimitou-se a população desta pesquisa aos supermercados situados na região metropolitana de Belo 
Horizonte, utilizando a amostragem por conveniência, organizados em sete redes interorganizacionais, totalizando 162 lojas, por entender que essas empresas possuem maior interesse em se organizar para ter sucesso empresarial.

Ao final de dois meses de contatos, foram obtidos 60 questionários, distribuídos nas redes, A Tabela 1 apresenta os dados do total de lojas organizadas em rede, o total de lojas participantes e seu percentual de participação.

\begin{tabular}{|c|c|c|c|}
\hline REDE & $\begin{array}{l}\text { QUANT. LOJAS ORGANIZADAS } \\
\text { EM REDE }\end{array}$ & $\begin{array}{l}\text { QUANT. DE LOJAS } \\
\text { PARTICIPANTES }\end{array}$ & $\begin{array}{l}\% \text { DE } \text { LOJAS } \\
\text { PARTICIPANTES }\end{array}$ \\
\hline Arrastão & 37 & 14 & 37,84 \\
\hline Fácil & 19 & 7 & 36,84 \\
\hline Gerais & 5 & 2 & 40,00 \\
\hline Mania & 23 & 8 & 34,78 \\
\hline Paranaíba & 13 & 5 & 38,46 \\
\hline Super Varejista & 36 & 13 & 36,11 \\
\hline Valor & 29 & 11 & 37,93 \\
\hline TOTAL & 162 & 60 & $37,04 \%$ \\
\hline
\end{tabular}

Tabela 1 - Distribuição das lojas de acordo com as redes da região metropolitana de Belo Horizonte Fonte: Dados da Pesquisa.

O percentual de lojas participantes representam $37,04 \%$ da população de estudo. Foi feito um esforço por parte dos pesquisadores para que nenhuma rede fosse representada por menos de $30 \%$ de suas lojas associadas, a fim de melhorar a representatividade da amostra.

Com o auxílio do programa Microsoft Excel foram tabulados os dados e elaborados os gráficos que permitiram a caracterização e a análise do perfil dos estabelecimentos e dos gestores dos varejos supermercadistas da região metropolitana de Belo Horizonte.

\section{Análise empírica}

Os respondentes do questionário foram os proprietários dos varejos supermercadistas pertencentes às redes da região metropolitana de Belo Horizonte. Apurou-se que a idade média entre esses respondentes é de 49,1 anos. Um fato interessante observado é que nenhum dos supermercados possui gestor contratado. Ou seja, em todos os 60 supermercados o próprio dono é quem o administra.

Considerando os varejos supermercadistas que responderam ao questionário, 40 são filiados à AMIS, o que representa $66,66 \%$ da amostra, enquanto que 20 não são filiados, representando $33,33 \%$ da amostra.

Em relação ao nível de educação formal, os proprietários dos supermercados que possuem ensino superior representam $27 \%$ da amostra (16 pessoas), enquanto $10 \%$ ( 6 pessoas) ainda possuem apenas o ensino fundamental incompleto. A maior parte da amostra 42\% (25 pessoas) possui o ensino médio completo e $22 \%$ (13 pessoas) possuem o ensino médio incompleto. A Tabela 2 sumariza a distribuição dos respondentes quanto 0 grau de escolaridade.

\begin{tabular}{lllll}
\hline \hline \multirow{2}{*}{ Grau de escolaridade } & $\begin{array}{l}\text { Ensino fundamental } \\
\text { incompleto }\end{array}$ & $\begin{array}{l}\text { Ensino médio } \\
\text { incompleto }\end{array}$ & $\begin{array}{l}\text { Ensino médio } \\
\text { completo }\end{array}$ & $\begin{array}{l}\text { Ensino } \\
\text { superior }\end{array}$ \\
\hline Quant. & 6 & 13 & 25 & 16 \\
$\%$ & 10 & 22 & 42 & 27 \\
\hline \hline
\end{tabular}

Tabela 2 - Grau de escolaridade

Fonte: Dados da pesquisa 
O grau de escolaridade mais presente na formação dos proprietários dos varejos supermercadistas das redes foi o ensino médio (completo ou não), sendo 38 proprietários nesta faixa, ou 64\% do total da amostra.

\section{Análise dos estabelecimentos quanto ao tempo de funcionamento}

A maior parte da amostra é representada por estabelecimentos com mais de 15 anos de existência (45\%), sendo 27 supermercadistas. Não houve nenhum supermercado participante constituído há menos de dois anos, enquanto que o número de quatro supermercados (representando $7 \%$ da amostra) foi constituído entre dois e cinco anos. A Tabela 3 sumariza as informações sobre o tempo de funcionamento dos estabelecimentos pesquisados.

\begin{tabular}{|c|c|c|c|c|c|c|c|}
\hline Item & Tempo & $\begin{array}{l}\text { Até } \\
\text { anos }\end{array}$ & $\begin{array}{c}2 \text { de } 2 \text { a } \\
\text { anos }\end{array}$ & $\begin{array}{c}5 \text { de } 5 \text { a } 8 \\
\text { anos }\end{array}$ & de 8 a 11 anos & $\begin{array}{l}\text { de } 11 \text { a } 15 \\
\text { anos }\end{array}$ & $\begin{array}{l}\text { mais de } 15 \\
\text { anos }\end{array}$ \\
\hline \multirow{2}{*}{$A$} & Quant. & 0 & 4 & 6 & 12 & 11 & 27 \\
\hline & $\%$ & 0 & 7 & 10 & 20 & 18 & 45 \\
\hline
\end{tabular}

Tabela 3 - Análise dos estabelecimentos quanto ao tempo de funcionamento

Fonte: Dados da pesquisa.

Os supermercados inaugurados entre cinco e oito anos tiveram seis representantes ( $10 \%$ da amostra); os inaugurados entre oito e onze anos, 12 , (20\% da amostra) e constituídos de 11 a 15 anos, 11 (18\%).

Análise dos estabelecimentos quanto às seções que fazem parte da loja

A Tabela 4 a seguir, apresenta a divisão de seções dos supermercados pesquisados.

\begin{tabular}{|c|c|c|c|c|c|c|c|c|c|}
\hline Item & Seções & Mercearia & $\begin{array}{l}\text { Frios e } \\
\text { Laticínios }\end{array}$ & $\begin{array}{l}\text { Carnes e } \\
\text { aves }\end{array}$ & $\begin{array}{l}\text { Horti } \\
\text { fruiti }\end{array}$ & Bazar & Padaria & Peixaria & Pet Shop \\
\hline \multirow{2}{*}{ B } & Quant. & 60 & 60 & 60 & 45 & 38 & 36 & 21 & 18 \\
\hline & $\%$ & 100 & 100 & 100 & 75 & 63 & 60 & 35 & 30 \\
\hline
\end{tabular}

Tabela 4 - Análise dos estabelecimentos quanto às seções que fazem parte da loja

Fonte: Dados da pesquisa.

Foi pedido ao respondente para marcar as seções que fazem parte da loja. Ele poderia marcar todas. Isso explica o fato de ter tido até 60 respostas por seção.

Observa-se que $100 \%$ dos 60 supermercados possuem as seções Mercearia, Frios e Laticínios e Carnes e Aves. A seção Hortifruti consta em $75 \%$ dos pesquisados (45 supermercados); Bazar, em $63 \%$ (38 supermercados); Padaria, em 60\% (36 supermercados); e Peixaria, em 35\% (21 supermercados). Citaram a opção "Outras Seções" 30 \% dos supermercados, incluindo aí a seção Pet Shop, onde vendem rações para diversos animais, assim como outros itens para gatos, cachorros e pássaros.

É importante citar que $25 \%$ dos supermercados (6 unidades) que não possuem padaria, ou seja, compram o pão pronto para assar em um miniforno e o vendem. Ressalta-se, ainda, que duas seções incluídas no questionário, Têxtil e Eletrodoméstico, não são utilizadas por nenhum dos supermercados participantes da pesquisa.

\section{Análise dos estabelecimentos quanto ao número de colaboradores}

A maior parte das empresas, representando 30\% da amostra (18 supermercados) tem entre 21 e 30 colaboradores (entre empregados e parentes), enquanto que a menor participação foi na faixa de 41 a 49 
colaboradores, que teve quatro supermercados, sendo $7 \%$ da amostra. Entre os resultados intermediários, destaca-se que nove empresas não possuem mais que 10 colaboradores ( $15 \%$ da amostra). Houve um equilíbrio na faixa de 11 a 20 colaboradores e na faixa de 31 a 40 com 10 (17\% da amostra) e 13 (22\% da amostra) colaboradores respectivamente.

A análise do número de colaboradores está evidenciada na Tabela 5.

\begin{tabular}{llllllll}
\hline \hline Item & $\begin{array}{l}\text { Número } \\
\text { colaboradores }\end{array}$ & Até $\mathbf{1 0}$ & de $\mathbf{1 1}$ até $\mathbf{2 0}$ & de $\mathbf{2 1}$ até $\mathbf{3 0}$ & de $\mathbf{3 1}$ até $\mathbf{4 0}$ & de $\mathbf{4 1}$ até $\mathbf{4 9}$ & mais de $\mathbf{4 9}$ \\
\hline C & $\begin{array}{l}\text { Quant. } \\
\%\end{array}$ & 9 & 10 & 18 & 13 & 4 & 6 \\
& 15 & 17 & 30 & 22 & 7 & 10 \\
\hline
\end{tabular}

Tabela 5 - Análise dos estabelecimentos quanto ao número de colaboradores

Fonte: Dados da pesquisa.

Conforme o SEBRAE (2012), o critério de classificação do porte dos empreendimentos leva em conta o número de colaboradores, estabelecendo que a pequena empresa não deve ter mais do que 49 empregados nos ramos de comércio e serviços. Assim, com base neste critério, seis supermercados (10\% da amostra) não poderiam ser considerados pequenos. No entanto, foi observado que as demais características deles se assemelham muito aos outros estabelecimentos pertencentes à amostra por isso decidiu-se por mantêlos na análise.

Confrontando os resultados desta pesquisa com os resultados apresentados pela AMIS (2012), tem-se que o número médio de empregados no varejo supermercadista era de 18,2 e nesta pesquisa, que utilizou apenas lojas associadas a redes, encontrou-se a média de 27,05 colaboradores por supermercado.

\section{Análise dos estabelecimentos quanto à área de vendas}

O varejo supermercadista tem a maior concentração dos estabelecimentos entre $200 \mathrm{~m}^{2}$ e $500 \mathrm{~m}^{2}$, representando dois terços da amostra $(66,6 \%)$, sendo 40 o total de supermercados nesta faixa, conforme apresentado na Tabela 6.

\begin{tabular}{|c|c|c|c|c|c|c|c|}
\hline $\begin{array}{l}\text { Ite } \\
\text { m }\end{array}$ & $\begin{array}{l}\text { Área de vendas } \\
\left(\mathrm{M}^{2}\right)\end{array}$ & até 200 & $\begin{array}{l}\text { de } 201 \text { até } \\
300\end{array}$ & $\begin{array}{l}\text { de } 301 \text { até } \\
400\end{array}$ & $\begin{array}{l}\text { de } 401 \text { até } \\
500\end{array}$ & $\begin{array}{l}\text { de } 501 \text { até } \\
750\end{array}$ & $\begin{array}{l}\text { mais de } \\
750\end{array}$ \\
\hline ח & Quant. & 0 & 15 & 8 & 17 & 6 & 14 \\
\hline U & $\%$ & 0 & 25 & 13 & 28 & 10 & 23 \\
\hline
\end{tabular}

Tabela 6 - Análise dos estabelecimentos quanto à área de vendas da loja em $\mathrm{m}^{2}$

Fonte: Dados da pesquisa.

Não houve nenhum supermercado menor que $200 \mathrm{~m}^{2}$ de área de vendas, seis supermercados possuem área de vendas entre 500 e $750 \mathrm{~m}^{2}$ correspondendo a $10 \%$ da amostra e os outros $23 \%$, que representam 14 supermercados, possuem mais de $750 \mathrm{~m}^{2}$ de área de vendas.

Os supermercados com área de vendas maior que $400 \mathrm{~m}^{2}$ e menor que $500 \mathrm{~m}^{2}$ têm a maior participação na amostra que pesquisada, demonstrando que esta é a faixa que mais se identifica com o pequeno varejo supermercadista da região metropolitana de Belo Horizonte organizada em redes.

\section{Análise dos estabelecimentos quanto ao número de checkouts}

Conforme a Tabela 7 , nove supermercados ( $15 \%$ da amostra) têm menos de três checkouts. Não houve nenhum supermercado com mais de 15 checkouts. Há a concentração de 24 supermercados na faixa de 4 a 5 checkouts, o que representa $40 \%$ da amostra. Entre o mínimo de 6 e o máximo 15 checkouts concentram-se 27 supermercados, que representam $46 \%$ da amostra. 


\begin{tabular}{llllllll}
\hline \hline Item & $\begin{array}{l}\text { Número de } \\
\text { checkouts }\end{array}$ & até $\mathbf{3}$ & de $\mathbf{4}$ até $\mathbf{5}$ & de $\mathbf{6}$ até $\mathbf{7}$ & de $\mathbf{8}$ até $\mathbf{9}$ & de $\mathbf{1 0}$ até $\mathbf{1 5}$ & mais de $\mathbf{1 5}$ \\
\hline $\mathrm{E}$ & $\begin{array}{l}\text { Quant. } \\
\%\end{array}$ & 9 & 24 & 13 & 4 & 10 & 0 \\
\hline \hline
\end{tabular}

Tabela 7 - Análise dos estabelecimentos quanto ao número de checkouts na loja

Fonte: Dados da pesquisa.

Comparando os achados desta pesquisa com os resultados do estudo realizado pela AMIS (2012), constatase que o número médio era 3,6 checkouts e que nesta pesquisa a média encontrada foi de 6,16 checkouts por estabelecimento. Um fato interessante observado é que, se forem excluídos do cálculo os dez maiores supermercados da amostra, que possuem entre 10 e 15 checkouts, a média do grupo (demais 50 supermercados) ficou em 4.08 checkouts.

\section{Análise dos estabelecimentos quanto ao número de itens cadastrados}

Conforme a Tabela 8, o número de supermercados que possuem mais de 15 mil itens cadastrados representa $32 \%$ da amostra, sendo que os demais $68 \%$ estão assim divididos: $25 \%$ entre 6 e 9 mil itens, $27 \%$ entre 9 e 12 mil itens e $17 \%$ entre 12 e 15 mil itens cadastrados.

\begin{tabular}{llllllllll}
\hline \hline Item & $\begin{array}{l}\text { Número de } \\
\text { itens } \\
\text { cadastrados }\end{array}$ & até 3000 & $\begin{array}{l}\text { de } 3001 \\
\text { até } \mathbf{6 0 0 0}\end{array}$ & $\begin{array}{l}\text { de } 6001 \\
\text { até } 9000\end{array}$ & $\begin{array}{l}\text { de } 9001 \\
\text { até } 12000\end{array}$ & $\begin{array}{l}\text { de } 12001 \\
\text { até } 15000\end{array}$ & 15000 & de \\
\hline $\mathrm{F}$ & $\begin{array}{l}\text { Quant. } \\
\%\end{array}$ & 0 & 0 & 15 & 16 & 10 & 19 \\
& 0 & 0 & 25 & 27 & 17 & 32 \\
\hline \hline
\end{tabular}

Tabela 8 - Análise dos estabelecimentos quanto o número de itens cadastrados

Fonte: Dados da pesquisa

Do total de 60 supermercados pesquisados, 26 têm em seu cadastro no mínimo 9 mil e no máximo 15 mil itens cadastrados, o que representa $44 \%$ da amostra.

A diferença entre o número de itens cadastrados e número de itens ativos é que o primeiro denota o universo de cadastros do supermercado, sem, no entanto, a obrigação de ter o produto na gôndola, enquanto 0 segundo (itens ativos) denota os produtos que efetivamente estão disponíveis para os clientes comprarem, assunto explorado na sequência.

\section{Análise dos estabelecimentos quanto número de itens ativos}

Na prática, o número de itens ativos é que irá denotar realmente o tamanho do supermercado. 0 número de supermercados que possuem mais de 15 mil itens ativos representa $27 \%$ da amostra, enquanto que 0 número de supermercados que possuem menos que 6 mil itens ativos representa $17 \%$ da amostra, conforme a Tabela 9 .

\begin{tabular}{|c|c|c|c|c|c|c|c|}
\hline Item & $\begin{array}{l}\text { Número de } \\
\text { itens ativos }\end{array}$ & $\begin{array}{l}\text { até } \\
3000\end{array}$ & $\begin{array}{l}\text { de } 3001 \text { até } \\
6000\end{array}$ & $\begin{array}{l}\text { de } 6001 \text { até } \\
9000\end{array}$ & $\begin{array}{l}\text { de } 9001 \text { até } \\
12000\end{array}$ & $\begin{array}{l}\text { de } 12001 \text { até } \\
15000\end{array}$ & $\begin{array}{l}\text { mais de } \\
15000\end{array}$ \\
\hline \multirow{2}{*}{ G } & Quant. & 0 & 10 & 19 & 11 & 4 & 16 \\
\hline & $\%$ & 0 & 17 & 32 & 18 & 7 & 27 \\
\hline
\end{tabular}

Tabela 9 - Análise dos estabelecimentos quanto o número de itens ativos

Fonte: Dados da pesquisa 
Do total de 60 supermercados pesquisados, 30 têm em seu cadastro no mínimo 6 mil e no máximo 12 mil itens ativos, o que representa $50 \%$ da amostra. O número de itens ativos denota a escala de tamanhos da amostra pesquisada. Por fim, observa-se que o microempreendedor (área de vendas menor que $200 \mathrm{~m}^{2} \mathrm{e}$ menos de 3 mil itens cadastrados) não participa das redes pesquisadas. Essas são compostas de pequenos empreendedores com ampla variedade de classes.

\section{Análise dos estabelecimentos quanto o faturamento}

A Tabela 10 demonstra que $18 \%$ dos supermercados pesquisados faturam entre $\mathrm{R} \$ 150$ e $\mathrm{R} \$ 300$ mil por mês, o que, somado aos supermercados que faturam entre $\mathrm{R} \$ 300$ e $\mathrm{R} \$ 450$ mil (27\%), forma uma concentração de $45 \%$ da amostra com faturamento até e $R \$ 450$ mil reais por mês. 0 intervalo de faturamento entre $\mathrm{R} \$ 450$ mil e $\mathrm{R} \$ 750$ mil tem 14 supermercados, o que representa $23 \%$, enquanto que 19 supermercados faturam mais de $\mathrm{R} \$ 750$ mil, representando $32 \%$ da amostra.

\begin{tabular}{|c|c|c|c|c|c|c|c|}
\hline Item & $\begin{array}{l}\text { Faturamento } \\
\text { médio mensal } \\
\text { em R\$ }\end{array}$ & até 150 Mil & $\begin{array}{l}\text { de } 150 \text { até } \\
300 \mathrm{Mil}\end{array}$ & $\begin{array}{l}\text { de } 300 \text { até } \\
450 \text { Mil }\end{array}$ & $\begin{array}{l}\text { de } 450 \text { até } \\
600 \text { Mil }\end{array}$ & $\begin{array}{l}\text { de } 600 \text { até } \\
750 \text { Mil }\end{array}$ & $\begin{array}{l}\text { mais de } \\
750 \text { Mil }\end{array}$ \\
\hline \multirow{2}{*}{$\mathrm{H}$} & Quant. & 0 & 11 & 16 & 8 & 6 & 19 \\
\hline & $\%$ & 0 & 18 & 27 & 13 & 10 & 32 \\
\hline
\end{tabular}

Tabela 10 - Análise dos estabelecimentos quanto ao faturamento

Fonte: Dados da pesquisa

Nenhum dos supermercados pesquisados faturou menos que $\mathrm{R} \$ 150$ mil mensais. Pode-se perceber que os supermercados organizados em redes mantêm um tamanho mínimo capaz de suportar a estrutura necessária para assegurar a competitividade e, consequentemente, a sustentabilidade financeira empresarial.

\section{Resumo dos itens de maior representatividade na caracterização do pequeno varejo supermercadista da região metropolitana de Belo Horizonte}

Em relação ao tempo de funcionamento, a característica predominante supera 15 anos de funcionamento, mostrando a maturidade dos empreendedores que participaram da pesquisa. Todos os varejos supermercadistas contemplam as seções de Frios e Laticínios, Mercearia e Carnes e Aves. Já com relação ao número de colaboradores, a faixa predominante é a de 21 a 30 colaboradores. Esses e outros dados são apresentados no Quadro 3, que apresenta a compilação dos valores médios calculados para cada característica analisada, considerando a média aritmética calculada para os intervalos de cada grupo.

\begin{tabular}{|l|l|l|}
\hline Descrição das características & Característica predominante & Média do grupo \\
\hline Tempo de funcionamento & Mais de 15 anos & 12,82 \\
\hline Seções que fazem parte da loja & Mercearia, Frios e Laticínios, Carnes e Aves & - \\
\hline Número de colaboradores & De 21 a 30 colaboradores & 27,05 \\
\hline Área de vendas da loja & De $401 \mathrm{~m}^{2}$ até $500 \mathrm{~m}^{2}$ & 503,83 \\
\hline Número de checkouts & De 4 a 5 checkouts & 6,16 \\
\hline Número de itens cadastrados & Mais de 15.000 itens & 12.151 \\
\hline Número de itens ativos & Entre 6.000 a 9.000 itens & 10.351 \\
\hline Faturamento médio mensal & Acima de $\mathrm{R} \$ 750$ mil & $\mathrm{R} \$ 635.000$ \\
\hline
\end{tabular}

Quadro 3 - Resumo da caracterização do pequeno varejo supermercadista

Fonte: Elaborado pelo autor

Os varejos supermercadistas pesquisados tiveram a maior concentração quanto à característica de área de 
vendas entre $400 \mathrm{~m}^{2}$ e $500 \mathrm{~m}^{2}$. Já quanto ao número de checkouts, a característica predominante foi de 4 a 5 por loja.

É bem provável que os supermercados tenham muitos itens que deverão ser tirados de linha definitivamente, pois a maior concentração de supermercados quanto a itens cadastrados ficou acima de 15 mil itens cadastrados. Com relação a itens ativos a maior concentração ficou entre 6 mil e 9 mil itens.

Por fim, o faturamento mensal predominante foi superior a $\mathrm{R} \$ 750$ mil indicando a necessidade premente de profissionalização das empresas, a fim de alinhar o porte com sistemas de gestão adequados, para garantir sustentabilidade e longevidade.

\section{Considerações finais}

Estabeleceu-se como objetivo descrever como os estabelecimentos pertencentes ao pequeno varejo supermercadista da região metropolitana de Belo Horizonte organizado em redes está se estruturando. Foram explorados aspectos do varejo supermercadista, notadamente organizado em redes, suas origens e características.

Assim foram investigadas as características dos supermercadistas. Uma característica predominante dos gestores dos estabelecimentos pertencentes ao pequeno varejo supermercadista da região metropolitana de Belo Horizonte em relação ao tempo de funcionamento é a maturidade dos empreendedores que participaram da pesquisa, pois 32\% superaram 15 anos de funcionamento e a média geral foi de 12,82 anos.

Todos os varejos supermercadistas pesquisados contemplam as seções de Frios e Laticínios, Mercearia e Carnes e Aves. Com relação ao número de colaboradores, a faixa predominante é a de 21 a 30 colaboradores e a média, de 27,5 . Quanto à área de vendas, a maior concentração foi entre $400 \mathrm{~m}^{2}$ e $500 \mathrm{~m}^{2}$, sendo a média de $503,83 \mathrm{~m}^{2}$. O número de checkouts predominante foi de 4 a 5 por loja e a média foi de 6,16. A maior concentração de itens ativos ficou entre 6 mil e 9 mil itens. A média atingiu 10.351 itens, explica-se isso por $27 \%$ do varejo supermercadista entrevistado ter mais de 15 mil itens ativos.

O faturamento mensal predominante foi superior a $\mathrm{R} \$ 750$ mil e o faturamento médio mensal foi de $\mathrm{R} \$ 635$ mil, indicando a necessidade premente de profissionalização para alinhar o porte das empresas com sistemas de gestão adequados, de modo garantir sustentabilidade e longevidade empresarial.

Surpreendeu o porte das lojas, supermercados de bairro com abrangência reduzida e altos faturamentos, chegando algumas a faturar mais de $\mathrm{R} \$ 750$ mil por mês, indicando que a estruturação em redes favoreceu 0 crescimento. De outro lado, também chamou atenção o fato de não ter entre as redes nenhuma loja inaugurada há menos de dois anos, sinal de que quem está em um mercado altamente competitivo luta para se manter e fortalecer seu negócio, não se arriscando a inaugurar novas lojas nos últimos dois anos. Ressalta, ainda, que $63 \%$ das lojas estão estabelecidas há mais de dez anos no mercado, indicando 0 fortalecimento da confiança por meio da proximidade entre o proprietário e a clientela.

Para pesquisas futuras, sugere-se a ampliação da realidade estudada, assim como a realização de pesquisa conjunta com supermercados não associados a redes, de forma a comparar dados mais recentes.

${ }^{1}$ RICHERT, Henry G. Retailing: principles and practices. 3. Ed. New York: McGraw-Hill, 1954.

\section{Referências}

ABRAS - Associação Brasileira de Supermercados. Faça chuva ou sol, setor cresce. Disponível em: $<$ http://www.abrasnet.com.br/economia-e-pesquisa/ranking-abras/os-numeros-do-setor/>. Acesso em 03 out. 2012.

ABRAS - Associação Brasileira de Supermercados. Estatística das Redes de Pequenos Supermercados Brasileiros. Disponível em: http://www.abrasnet.com.br/, acesso em 20/02/2013. 
ALVES, Rosália Rodrigues; FIGUEIRA, Mariane; CASTRO, Cleber de Castro; SUGANO, Joel Yutaka; SOARES, Ari de Souza. Innovation Processes in Small and Medium Enterprises Associated in Networks from the Supermarket Sector. Journal of Technology Management \& Innovation, V.8, Special Issue, pp. 61-71, 2013.

AMIS - Associação Mineira de Supermercados. Supermercados mineiros se destacam no Ranking Abras 2017. Disponível em: < http://www.portalamis.org.br/?secao=noticias\&id=2594 > acesso: 14/06/17.

AMIS - Associação Mineira de Supermercados. Vendas dos supermercados mineiros crescem 3,74\% em abril. 2017. Disponível em: <http://www.portalamis.org.br/?secao=noticias\&id=2740>. Acesso: 14/06/17.

AMIS - Associação Mineira de Supermercados. Perspectivas de investimentos e crescimento do setor 2012/2013. Belo Horizonte/ MG, 2013.

BARBOSA, Jose Geraldo Pereira, ALMEIDA, Jozias Castro de, VILLELA, Lamounier Erthal. Redes de Pequenos e Médios Supermercados: um Estudo Exploratório dos Fatores Determinantes de Competitividade. XI Seminários em Administração, 2008, São Paulo. Anais...São Paulo/SP: XI SEMEAD, 2008.

BEIJERSE, R.P. uit. Knowledge management in small and medium-sized companies: Knowledge management for entrepreneurs. Journal of Knowledge Management, V.4, Issue 2, pp. 162, Kempston: 2000.

BEUREN, Ilse Maria (Organizadora). Como Elaborar Trabalhos Monográficos em Contabilidade. 3. ed. São Paulo/SP: Atlas, 2008.

BOEHE, Dirk; SILVA, Karen Menger. Rumo a uma estratégia de desenvolvimento de redes de PME's. In: XXVII Encontro da Anpad. 2003, Atibaia-SP. Anais... Atibaia-SP: XXVII EnANPAD, 2003.

BRASIL. Lei 11.638 de 28 de dezembro de 2007. Regulamento das Sociedades Anônimas. Disponível em http://www.planalto.gov.br/ccivil_03/_ato2007-2010/2007/ lei//11638.htm, acessado em 25/12/2013.

BRASIL. Portal Empreendedor. Mapa das micro e pequenas empresas. Disponível em: http://www.brasil.gov.br/empreendedor/empreendedorismo-hoje/o-mapa-das-micro-e-pequenas-empresas. Acesso em: 20 dez. 2012.

BRASIL, Lei Complementar 123/2006. Disponível em: http://www.planalto.gov.br/ccivil_03/leis/LCP/Lcp123.htm. Acesso em 20 dez. 2012.

BRITO, Luis Artur Ledur; VASCONCELOS, Flavio Carvalho de. Desempenho das empresas brasileiras: efeitos ano, ramo de negócios e firma individual. Revista de Administração Contemporânea, v. $9,1^{a}$ ed. Especial, p. 65-85, 2005.

CAMPOS, Larissa Couto et al. Gestão de Custos Interorganizacionais: Um Estudo da "Rede Cerrado" de Supermercados. Contabilidade Vista \& Revista, v. 27, n. 3, p. 81-104, 2016.

DIÁRIO DO COMÉRCIO. Criação de empresas cresce 16,6\%. Disponível em: < http://www.diariodocomercio.com.br/noticia.php?tit=criacao_de_empresas_cresce_16,6\&id=181191 > Acesso: 12/06/17.

ESTIVALETE, Vania de Fátima; PEDROZO, Eugenio Avila Pedrozo; CRUZ, Luciano Barin. The Learning Process in Interorganizational Relationships. BAR- Brazilian Administration Review, V.5, Issue 4, art. 5, pp. 319-331, October/December 2008.

FERREIRA, Roberto do Nascimento et al. Redes Organizacionais no Varejo Alimentar. In: XXXII Encontro da Anpad, 2008, Rio de Janeiro/RJ. Anais... Rio de Janeiro/RJ: XXXII EnANPAD, 2008.

FERRONATO, Airton João. Gestão Contábil-Financeira de Micro e Pequenas Empresas: Sobrevivência e Sustentabilidade. São Paulo: Atlas, 2011. 
GRONUM, Sarel; VERREYNNE, Martie-Louise; KASTELLE, Tim. The role of networks in small and mediumsized enterprise innovation and firm performance. Journal of Small Business Management, v. 50, n. 2, p. 257-282, 2012.

KARTHIK, N. S. I. Learning in strategic alliances: an evolutionbary perspective. Academy of marketing Science Review, V.2002, n. 10, pp.1-14, 2002.

KLEIN, Leander Luiz; PEREIRA, Breno Augusto Diniz. Reasons that lead companies to withdraw from interorganizational networks. Global Economics and Management Review, 2016.

LAS CASAS, Alexandre Luzzi. Marketing de Varejo. 2. Ed. São Paulo: Atlas, 2000.

LENZI, Fernando César; KIESEL, Marcio Daniel, Orgs. Empreendedor de Visão. São Paulo: Atlas, 2009.

MATIAS, Alberto Borges (Coordenador). Finanças corporativas de curto prazo: a gestão do valor do capital de giro. São Paulo: Atlas, 2007a.

MATIAS, Alberto Borges (Coordenador). Finanças corporativas de longo prazo: criação de valor com sustentabilidade financeira. São Paulo: Atlas, 2007b.

MELO, Natália Máximo. Centrais de Negócios de Pequenas Empresas do setor Supermercadista: Entre a Concorrência e a Cooperação. Revista Intratextos, Rio de Janeiro. vol.2, nº 1, pp. 76 - 96, 2010.

MENDES, Flávia Cristina Martins. Sustentabilidade no varejo: as práticas ambientais e suas implicações na consolidação da marca institucional. Dissertação de mestrado. Universidade de são Paulo - Escola de Comunicação e Artes, Departamento de Relações Públicas, Propaganda e Turismo. SP, 2012.

MESQUITA, José Marcos Carvalho de. Atributos explicativos da intenção de recompra em supermercados. Tese apresentada ao Centro de Pós-Graduação e Pesquisas em Administração da Universidade Federal de Minas Gerais. Belo Horizonte/MG, 2004.

PEREIRA, Breno Augusto Diniz; PEDROZO, Eugênio Ávila. Empreendedorismo Coletivo é Possível? Uma Análise do Processo de Constituição de Relacionamentos Cooperativos em Rede. In: XXIX Encontro da Anpad, 2005, Brasília/DF. Anais... Brasília/DF: EnANPAD, 2005.

RIBOLDAZZI, Sabina. Corporate Governance And Sustainability In Italian Large-Scale Retail Companies. European Scientific Journal, v. 12, n. 16, 2016.

ROLT, Carlos Roberto de; DIAS, Júlio da Silva; PEÑA, Francisco Tiago Garcia. Network analysis as a management tool for inter-organizational projects. Gestão \& Produção, n. AHEAD, p. 0-0, 2017.

SEBRAE. Serviço Brasileiro de Apoio a Micro e Pequena Empresa. Estratégia para enfrentar grandes concorrências. Boletim Oportunidades e Negócios. Set/2011. Disponível em: <www.sebrae.com.br>. Acesso em 08 de out. 2012.

SEBRAE. Serviço Brasileiro de Apoio a Micro e Pequena Empresa. Critérios de classificação de empresas: El - ME - EPP. Disponível em: http://www.sebrae-sc.com.br/leis/default.asp?vcdtexto=4154. Acesso em: 20 de out. 2012.

WILDER, Ariel. Mudanças no setor supermercadista e a formação de associações de pequenos supermercados. Dissertação de Mestrado. Escola Superior de Agricultura Luiz de Queiroz. Piracicaba SP, 2003.

${ }^{*}$ Agradecimento à FAPEMIG pelo apoio no desenvolvimento do estudo. 